\title{
Anterior segment intraocular metallic foreign body causing chronic hypopyon uveitis
}

\author{
Güler Mete • Yılmaz Turgut • Arslanhan Osman • \\ Ülkü Gülșen • Artaș Hakan
}

Received: 29 September 2010 / Accepted: 22 October 2010 / Published online: 17 November 2010

(C) The Author(s) 2010. This article is published with open access at Springerlink.com

\begin{abstract}
Intraocular foreign body (IOFB) is a common association of penetrating ocular trauma. Early diagnosis and removal of IOFBs especially if they are metallic is very important to determine further management and the final result of treatment. Missed IOFB may present in different clinical aspects that may limit its detection and symptoms may only become apparent after a prolonged period of time. We report a case of a missed metallic intraocular foreign body in the anterior chamber over a 2-year period without causing severe inflammatory reaction and presented with uveitis later. A 42-year-old man presented with a progressive blurring of vision, pain, photophobia, and redness in the left eye for 3 months. He had a history of traffic accident 2 years ago and he was accepted to intensive care unit for 3 days. Three months ago, in another center, he was admitted to hospital for 1 week and intravitreal antibiotics and medical treatment were given for pain, photophobia, and redness in his left eye. In five o' clock meridian of the angle, there was an IOFB coated with hypopyon was observed under biomicrocopic magnification. Plain X-ray and computed tomography confirmed the foreign body in the
\end{abstract}

G. Mete $(\bowtie)$

Department of Ophthalmology, Harput State Hospital,

23119, Elazı̆̆, Turkey

e-mail: meteglr@yahoo.com

Y. Turgut $\cdot$ A. Osman • Ü. Gülșen

Departmant of Ophthalmology,

Elazığ Education and Research Hospital,

Elazı̆̆g, Turkey

A. Hakan

Department of Radiology,

Elazı ̆ Education and Research Hospital,

Elazığ, Turkey left eye. After obtaining informed consent from the patient, the foreign body was removed under local anesthesia.

Keywords Intraocular foreign body - Intraocular inflammation $\cdot$ Penetrating ocular trauma

\section{Introduction}

Penetrating ocular trauma is an important cause of vision loss and may be associated with the presence of intraocular foreign body (IOFB). Intraocular foreign bodies accompany $18-41 \%$ of open globe injuries [1]. Early diagnosis and removal of IOFBs is very important to determine further management and the final result of treatment. Furthermore, a missed IOFB may present a medicolegal liability for the physician. Up to $56 \%$ of medicolegal trauma cases are associated with missed IOFBs [2]. For these reasons, penetrating ocular injury require meticulous investigation and early intervention. Intraocular foreign bodies resulting from penetrating ocular injuries are usually detected at the first visit. However, missed IOFB may present in different clinical aspects that may limit its detection and symptoms may only become apparent after a prolonged period of time [3]. We report a case of a missed metallic intraocular foreign body in the anterior chamber over a 2-year period without causing severe inflammatory reaction and presented with uveitis later.

\section{Case report}

A 42-year-old man presented with a progressive blurring of vision, pain, photophobia, and redness in the left eye for 3 months. He had a history of traffic accident 2 years ago 
and he was admitted to intensive care unit for 3 days. We have no information about the ophthalmic examination and ocular symptoms of the patient at that time. Three months ago, in another center he was admitted to hospital for 1 week and intravitreal antibiotics and medical treatment were given for pain, photophobia, and redness in his left eye. On presentation, his best-corrected visual acuities were $20 / 20$ and $20 / 320$ in the right and in the left eye, respectively. The intraocular pressure was $14 \mathrm{mmHg}$ in the right eye and $18 \mathrm{mmHg}$ in the left eye. Biomicroscopic examination revealed chemosis, corneal edema, ciliary injection, flare, and $1.5 \mathrm{~mm}$ hypopyon in the left eye. In five o' clock meridian of the angle, there was an IOFB coated with hypopyon observed under biomicrocopic magnification (Fig. 1). A dilated pupil fundus examination revealed no abnormality. Plain X-ray and computed tomography confirmed the foreign body in the left eye (Fig. 2). After obtaining informed consent from the patient, the foreign body was removed under local anesthesia with foreign body forceps. The IOFB was metallic and its size was about $1.5 \times 2.5 \mathrm{~mm}$ (Fig. 3). After operation, best corrected visual acuities were $20 / 20$ and 20/100 in the right eye and in the left eye, respectively, and diffuse lens opacity was observed in the left eye.

\section{Discussion}

An IOFB is any material, organic, or inorganic, which penetrates into the ocular tissue. According to the literature, the vast majority of the patients with IOFB were male (94\%) and relatively young (mean, 33 years), with most in the working-age group. Metal-on-metal activities, particularly with various tools, are often associated with metallic IOFBs [4]. Typically, a small, high-speed projectile penetrates the eye and, possibly, finally lodges in the eye [5]. The foreign bodies may be classified as metallic or nonmetallic, with the

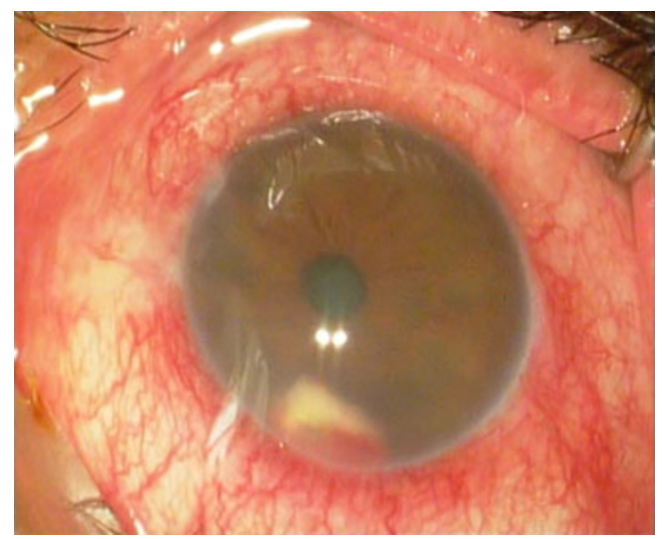

Fig. 1 In five o' clock meridian of the angle an IOFB coated with hypopyon is seen in the left eye

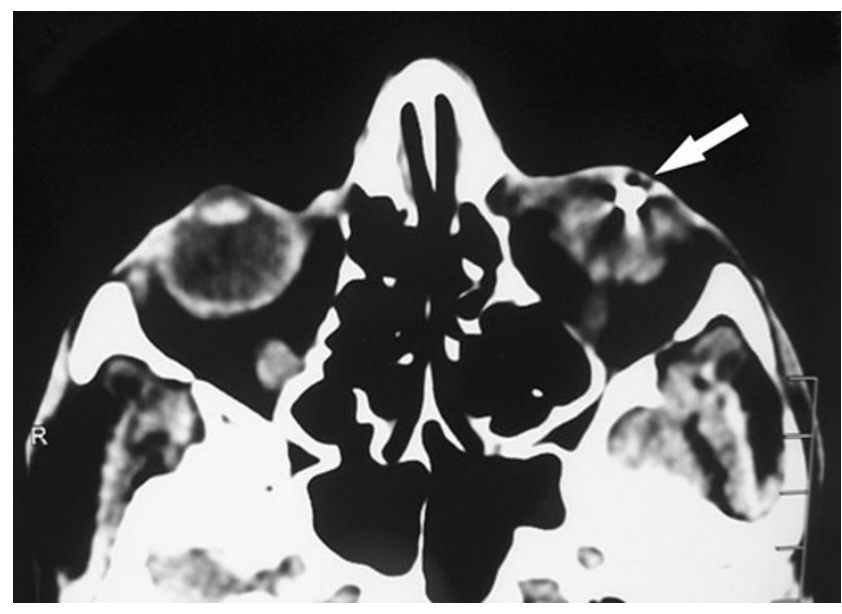

Fig. 2 Foreign body demonstrated on CT in the left eye

metallic being divided into magnetic and nonmagnetic. They are also classified into toxic and nontoxic [3]. Intraocular foreign bodies can cause mechanical, and also chemical injury if they contain iron (siderosis) or copper (chalcosis), but the most important risk of a retained foreign body is infection. For these reasons, IOFBs need prompt evaluation and management as they may quickly lead to sightthreatening complications. Management of such cases is not always easy and certain foreign bodies of inert material (those made of stone, plastic, glass, and inert metals such as gold, silver, and platinum) excite minimum inflammation and may remain quiescent for a long period [6].

Currently, there are many tools available to aid in diagnosis for IOFBs, including plain X-ray, ultrasonography, optical coherence tomography, anterior segment optical coherence tomography (ASOCT), ultrasound biomicroscopy, computerized tomography (CT) scanning, and magnetic resonance imaging. Plain X-ray is not useful for though glass, stone, and vegetative foreign bodies. Recently, $\mathrm{X}$-ray has been replaced by CT because of high negative results [7]. Magnetic resonance imaging can localize non-

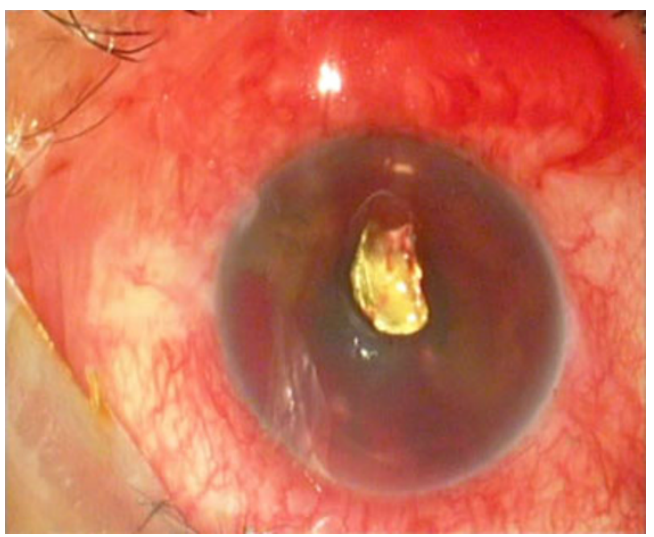

Fig. 3 The metallic foreign body removed from the anterior chamber angle 
metallic IOFB, but is contra-indicated in the case of metallic IOFBs and may produce motion artifacts [8]. Ultrasound can be usefull to detect the presence, location, and composition of IOFBs with high sensitivity, specificity, and accuracy [9]. Ultrasound biomicroscopy is a safe, noninvasive imaging tool for the localization of occult IOFBs located in the anterior segment and ciliary body [6]. Optical coherence tomography and ASOCT are also helpful in establishing the localization and size of the foreign body. They have the added advantage of being non-contact [10].

Our patient had undetected IOFB for 2 years. As mentioned before, our patient had a history of traffic accident 2 years ago and he was admitted to intensive care unit for 3 days. The location of the foreign body in the anterior chamber close to the chamber angle. These may be probable reasons for the misdignose. We did not perform chemical analyses to the metallic foreign body. But it was probably an alloy and major constituent of which was relatively inert. Similar cases have been reported where a foreign body was retained inside the lens for many years [11]. However, metallic intraocular foreign body lodged in the anterior chamber without any evident of metallosis for 2-year period is unusual. In the present case, we noted marked ocular inflammation. Intraocular inflammation unresponsive to intravitreal antibiotics aroused suspicion to the presence of an intraocular foreign body. Plain X-ray and CT confirmed the foreign body in the left eye. A retained foreign body should be considered in each patient with a history of ocular trauma and all efforts must be made to exclude presumptive diagnosis of intraocular foreign body.

Open Access This article is distributed under the terms of the Creative Commons Attribution Noncommercial License which per- mits any noncommercial use, distribution, and reproduction in any medium, provided the original author(s) and source are credited.

\section{References}

1. Mester V, Kuhn F (2002) Intraocular foreign bodies. Ophthalmol Clin North Am 15(2):235-242

2. Bettman JW (1990) Seven hundred medicolegal cases in ophthalmology. Ophthalmology 97(10):1379-1384

3. Omoti AE, Dawodu OA, Ogbeide OU (2008) An unusual case of marble intraocular foreign body. Middle East Afr J Ophthalmol 15 (1):39-42. doi:10.4103/0974-9233.53375

4. Ehlers JP, Kunimoto DY, Ittoop S et al (2008) Metallic intraocular foreign bodies: characteristics, interventions, and prognostic factors for visual outcome and globe survival. Am J Ophthalmol 146(3):427-433. doi:10.1016/j.ajo.2008.05.021

5. Woodcock MG, Scott RA, Huntbach J, Kirkby GR (2006) Mass and shape as factors in intraocular foreign body injuries. Ophthalmology 113(12):2262-2269. doi:10.1016/j.ophtha.2006.06.002

6. Kaushik S, Ichhpujani P, Ramasubramanian A, Pandav SS (2008) Occult intraocular foreign body: ultrasound biomicroscopy holds the key. Int Ophthalmol 28(1):71-73. doi:10.1007/s10792-0079110-5

7. Dass AB, Ferrone PJ, Chu YR, Esposito M, Gray L (2001) Sensitivity of spiral computed tomography scanning for detecting intraocular foreign bodies. Ophthalmology 108(12):2326-2328

8. Lustrin ES, Brown JH, Novelline R, Weber AL (1996) Radiologic assessment of trauma and foreign bodies of the eye and orbit. Neuroimag Clin N Am 6(1):219-237

9. Sargsyan AE, Dulchavsky AG, Adams J et al (2008) Ultrasound detection of simulated intra-ocular foreign bodies by minimally trained personnel. Aviat Space Environ Med 79(1):58-61

10. Wylegala E, Dobrowolski D, Nowińska A, Tarnawska D (2009) Anterior segment optical coherence tomography in eye injuries. Graefes Arch Clin Exp Ophthalmol 247(4):451-455. doi:10.1007/ s00417-008-0937-X

11. Chang YS, Jeong YC, Ko BY (2008) A case of an asymptomatic intralenticular foreign body. Korean J Ophthalmol 22(4):272-275. doi:10.3341/kjo.2008.22.4.272 